\title{
Electronic structure of Fe- vs. Ru-based dye molecules
}

Johnson, Phillip S.; Cook, Peter L.; Zegkinoglou, loannis; García Lastra, Juan Maria; Rubio, Angel; Ruther, Rose E.; Hamers, Robert J.; Himpsel, F. J.

Published in:

Journal of Chemical Physics

Link to article, DOI:

$10.1063 / 1.4788617$

Publication date:

2013

Document Version

Publisher's PDF, also known as Version of record

Link back to DTU Orbit

Citation (APA):

Johnson, P. S., Cook, P. L., Zegkinoglou, I., García Lastra, J. M., Rubio, A., Ruther, R. E., Hamers, R. J., \& Himpsel, F. J. (2013). Electronic structure of Fe- vs. Ru-based dye molecules. Journal of Chemical Physics, 138(4), 044709. https://doi.org/10.1063/1.4788617

\section{General rights}

Copyright and moral rights for the publications made accessible in the public portal are retained by the authors and/or other copyright owners and it is a condition of accessing publications that users recognise and abide by the legal requirements associated with these rights.

- Users may download and print one copy of any publication from the public portal for the purpose of private study or research.

- You may not further distribute the material or use it for any profit-making activity or commercial gain

- You may freely distribute the URL identifying the publication in the public portal 


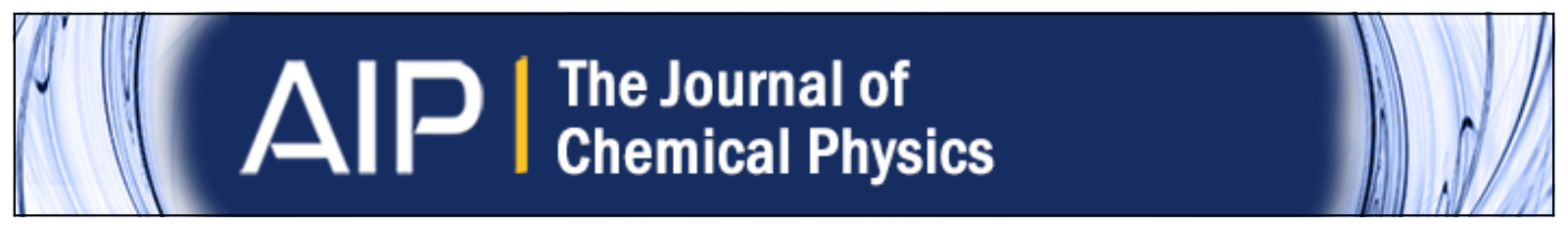

\section{Electronic structure of Fe- vs. Ru-based dye molecules}

Phillip S. Johnson, Peter L. Cook, loannis Zegkinoglou, J. M. García-Lastra, Angel Rubio, Rose E. Ruther, Robert J. Hamers, and F. J. Himpsel

Citation: The Journal of Chemical Physics 138, 044709 (2013); doi: 10.1063/1.4788617

View online: http://dx.doi.org/10.1063/1.4788617

View Table of Contents: http://scitation.aip.org/content/aip/journal/jcp/138/4?ver=pdfcov

Published by the AIP Publishing

\section{AlP Re-register for Table of Content Alerts}




\title{
Electronic structure of Fe- vs. Ru-based dye molecules
}

\author{
Phillip S. Johnson, ${ }^{1}$ Peter L. Cook, ${ }^{2}$ Ioannis Zegkinoglou, ${ }^{1,3}$ J. M. García-Lastra, ${ }^{4,5}$ \\ Angel Rubio, ${ }^{4}$ Rose E. Ruther, ${ }^{6}$ Robert J. Hamers, ${ }^{7}$ and F. J. Himpsel ${ }^{1}$ \\ ${ }^{1}$ Department of Physics, University of Wisconsin-Madison, 1150 University Ave., Madison, \\ Wisconsin 53706, USA \\ ${ }^{2}$ Natural Sciences Department, University of Wisconsin-Superior, Belknap and Catlin, Superior, \\ Wisconsin 54880, USA \\ ${ }^{3}$ Advanced Light Source, Lawrence Berkeley National Laboratory, 1 Cyclotron Road, Berkeley, \\ California 94720, USA \\ ${ }^{4}$ Dpto. Física de Materiales, Nano-Bio Spectroscopy Group and ETSF Scientific Development Centre, \\ Centro de Física de Materiales CSIC-UPV-MPC and DIPC, Universidad del País Vasco, Av. Tolosa 72, \\ E-20018 San Sebastían, Spain \\ ${ }^{5}$ Department of Physics, Center for Atomic-scale Materials Design, DTU, DK-2800 Kongens Lyngby, Denmark \\ ${ }^{6}$ NSF Center for Sustainable Materials Chemistry, Oregon State University, Corvallis, Oregon 97331-4003, \\ USA and University of Oregon, Eugene, Oregon 97403-1253, USA \\ ${ }^{7}$ Department of Chemistry, University of Wisconsin-Madison, 1101 University Ave., Madison, \\ Wisconsin 53706, USA
}

(Received 27 November 2012; accepted 4 January 2013; published online 28 January 2013)

\begin{abstract}
In order to explore whether Ru can be replaced by inexpensive Fe in dye molecules for solar cells, the differences in the electronic structure of Fe- and Ru-based dyes are investigated by X-ray absorption spectroscopy and first-principles calculations. Molecules with the metal in a sixfold, octahedral $\mathrm{N}$ cage, such as tris(bipyridines) and tris(phenanthrolines), exhibit a systematic downward shift of the $\mathrm{N} 1 s-$ to- $\pi *$ transition when Ru is replaced by Fe. This shift is explained by an extra transfer of negative charge from the metal to the $\mathrm{N}$ ligands in the case of $\mathrm{Fe}$, which reduces the binding energy of the $\mathrm{N} 1 s$ core level. The $\mathrm{C} 1 s$-to- $\pi *$ transitions show the opposite trend, with an increase in the transition energy when replacing Ru by Fe. Molecules with the metal in a fourfold, planar $\mathrm{N}$ cage (porphyrins) exhibit a more complex behavior due to a subtle competition between the crystal field, axial ligands, and the 2+ vs. 3+ oxidation states. (0) 2013 American Institute of Physics. [http://dx.doi.org/10.1063/1.4788617]
\end{abstract}

\section{INTRODUCTION}

Dye-sensitized solar cells frequently use metal-organic dye molecules containing the rare metal ruthenium, ${ }^{1}$ which hampers large-scale applications in photovoltaic power plants. On the other hand, similar types of charge transfer reactions are carried out in biological systems by heme-based molecules containing iron as the active redox center. Since Fe is located just above $\mathrm{Ru}$ in the periodic table, the question arises whether it is possible to use abundant $\mathrm{Fe}$ instead of the rare $\mathrm{Ru}$ for dye-sensitized solar cells. ${ }^{2}$ A similar question has come up in the context of Fe- versus Ru-based catalysts. ${ }^{3}$

Many different metal-organic dye molecules have been used for photovoltaics, ${ }^{1,4-6}$ but most of them are characterized by a metal atom surrounded by a cage of $\mathrm{N}$ atoms. The cage can be two-dimensional (in porphyrins and phthalocyanines) or three-dimensional (in polypyridyl structures). Systematic work on the electronic structure of two-dimensional dyes can be found in Refs. 4 and 7-11. For three-dimensional complexes, the electronic structure ${ }^{12-17}$ and charge transfer ${ }^{18-24}$ have been investigated using many spectroscopic ${ }^{25-31}$ and theoretical ${ }^{32-40}$ methods.

Despite the analogy between $\mathrm{Fe}$ and $\mathrm{Ru}$ in the periodic table, there are several subtle differences in their electronic structure. For example, $\mathrm{Fe}$ is significantly less electronegative than $\mathrm{Ru}$ ( 1.83 versus 2.2$)$ and thus more prone to transfer elec- tron charge to ligands. Both $\mathrm{Fe}$ and Ru exhibit a wide range of oxidation states (from -2 to +6 for $\mathrm{Fe}$ and from -2 to +8 for $\mathrm{Ru}$ ), but Fe prefers the +3 oxidation state while Ru prefers +2 and +4 , with +2 representing the typical oxidation state of Ru in dye molecules. A special feature of neutral Ru is the transfer of an outer $s$-electron to the $d$-shell, which leads to a different configuration of the active $d$-electrons. This is less important in dye molecules, where $\mathrm{Fe}$ and $\mathrm{Ru}$ are oxidized to $+2\left(d^{6}\right)$ or $+3\left(d^{5}\right)$.

The $3 d$ valence electrons of Fe differ from the $4 d$ electrons of Ru in several aspects. The smaller spatial extent of the $\mathrm{Fe} 3 d$ vs. $\mathrm{Ru} 4 d$ wave functions leads to a smaller bond length between Fe and N (see Sec. IV B for two-dimensional molecules and Ref. 41 for three-dimensional molecules). Superficially, this suggests a larger overlap between the metal $d$-electrons and the adjacent $\mathrm{N} 2 p$ electrons for Fe. On the other hand, the $\mathrm{N}$ cage is fairly stiff, particularly in planar dye molecules. It is not flexible enough to completely accommodate the difference in the ionic radii. Therefore, the overlap is smaller for $\mathrm{Fe}$, and likewise the hybridization between the metal $d$ electrons and the $\mathrm{N} 2 p$ electrons.

Like the hybridization, the crystal field splitting decreases substantially from the $4 d$ to the $3 d$ manifold. The lower crystal field splitting in Fe makes it possible to promote electrons from the filled $t_{2 g}$ to the empty $e_{g}$ states in 
order to have parallel spins. ${ }^{42}$ As a consequence, Ru tends to be in the low spin configuration while Fe can also occur in the high spin configuration. For example, the gap between the $t_{2 g}$ and $e_{g}$-derived states is $2.9 \mathrm{eV}$ for RuCO octaethyl porphyrin (OEP) and $0.8 \mathrm{eV}$ for $\mathrm{FeCl}$ octaethyl porphyrin according to our calculations.

An additional splitting is caused by the spin-orbit interaction, which can be quantified by the parameter $\zeta^{\prime}$ defined in Refs. 43 and 44 , which is $0.13 \mathrm{eV}$ for the $4 d$ electrons ${ }^{43}$ in atomic $\mathrm{Ru}^{2}+$ and $0.05 \mathrm{eV}$ for the $3 d$ electrons ${ }^{44}$ in atomic $\mathrm{Fe}^{2+}$. The different strength of the spin-orbit interaction affects the optical transitions in the visible and UV, particularly luminescence and circular dichroism. When compared to the interaction between the transition dipoles on the ligands, the spin-orbit interaction dominates in Ru-tris(phenanthroline) while being small in Fe-tris(phenanthroline) (see Table 1 in Ref. 40). That changes the sequence of the lowest excited orbitals from ${ }^{3} \mathrm{~A}_{2}<{ }^{1} \mathrm{~A}_{2}<{ }^{1} \mathrm{E}$ for $\mathrm{Ru}$ to ${ }^{1} \mathrm{E}<{ }^{3} \mathrm{~A}_{2}<{ }^{1} \mathrm{~A}_{2}$ for $\mathrm{Fe}$. The effect of the spin-orbit interaction on the electronic structure has been studied in detail for the Fe-, $\mathrm{Ru}$-, and Os-tris(bipyridine) series which covers the $3 d, 4 d$, and $5 d$ shells. ${ }^{12,45-47}$ Here, we restrict ourselves to the Fe-Ru comparison, but extend the scope to a broader class of dye molecules, i.e., tris(phenanthroline) and OEP in addition to tris(bipyridine).

The spin-orbit splitting affects the highest occupied molecular orbital (HOMO), which tends to have metal $d$ character, while the lowest unoccupied molecular orbital (LUMO) has usually $\mathrm{N} 2 p$ character in the metal-organic dye molecules discussed here. ${ }^{7,12}$ In a dye-sensitized solar cell, the HOMO is relevant to refilling the hole, which may occur from the donor or the acceptor (as undesirable back electron transfer). The LUMO mediates the extraction of excited electrons via injection into an oxide acceptor, such as $\mathrm{TiO}_{2}$. This part of the electron-hole separation involves very little voltage loss, but the lack of a strong driving potential makes it slow. A rapid refilling of the hole via the donor is required to minimize back electron transfer from the acceptor, and that entails a substantial loss of open circuit voltage. ${ }^{1,6}$ This has been a particular problem with Fe-based dyes.

The most glaring chemical difference between Fe and $\mathrm{Ru}$ is the resistance of $\mathrm{Ru}$ against oxidation, which is related to its higher electronegativity. This property is important for practical purposes (lifetime of a solar cell and necessity of careful encapsulation). For example, $\mathrm{Fe}^{2+}$-phthalocyanine has been found to oxidize in air to $\mathrm{Fe}^{3+}$ (Ref. 2), while $\mathrm{Ru}^{2+}$ phthalocyanines remain stable. ${ }^{14,48} \mathrm{Fe}^{2+}$-porphyrin appears to be even more difficult to stabilize. We were unable to desorb $\mathrm{Cl}$ from $\mathrm{FeCl}-\mathrm{OEP}$. In biomolecules, such as the heme, the central $\mathrm{Fe}$ atom is protected from oxidation by a threedimensional cage of $\mathrm{N}$ (or $\mathrm{S}$ ) atoms with approximately octahedral symmetry. This suggests searching for dye molecules containing $\mathrm{Fe}$ in similar octahedral cages, but without the protein backbone which is fragile and prone to radiation damage. ${ }^{49,50}$ This avenue will be pursued further in a separate publication. ${ }^{51}$ Overall, this research is part of a program to measure the energy levels relevant to the performance of solar cells. ${ }^{52}$ Such results provide the input for designing optimized combinations of materials for solar cells.
With this goal in mind we have investigated the differences in the electronic structure of Fe- and Ru-based dye molecules, combining X-ray absorption spectroscopy at the $\mathrm{N} 1 s$ and C $1 s$ edges with density functional theory (DFT). Thereby, we address the LUMO, which can be accessed by the same absorption edge (N $1 s$-to- $2 p$ ) for both Fe and Ru complexes (for previous work, see Refs. 12, 15, 19 and 29). Addressing the HOMO requires two different absorption edges, i.e., Fe $2 p$-to- $3 d$ at $0.7 \mathrm{keV}$ (see Refs. 23, 25, 26, 28, 30 and 31 ) and $\mathrm{Ru} 2 p$-to- $4 d$ at $2.8 \mathrm{keV}$ (see Ref. 19, 24, 27). Various core level absorption edges have been studied by ultrafast core level pump-probe techniques. ${ }^{23-29}$

The $\mathrm{N} 1 s$ absorption edge is of particular interest, because the immediate neighbors of the metal atom are $\mathrm{N}$ atoms in the dyes studied here. Their $\pi *$ orbitals tend to dominate the LUMO ${ }^{7}$ although occasionally one of the unoccupied metal $d$-orbitals drops below the lowest $\pi *$ level or hybridizes with it. ${ }^{13}$ The transition energy from the $\mathrm{N} 1 s$ core level to the LUMO is sensitive to the charge transfer between the metal atom and the surrounding $\mathrm{N}$ cage, as demonstrated for a series of OEPs with $3 d$ metals at the center. ${ }^{7}$ We find a similar charge transfer shift in a variety of Fe- and Ru-based dye molecules.

The key result can be summarized as follows: (1) There is a systematic downward shift of the $\mathrm{N} 1 s$-to- $\pi^{*}$ transition when replacing $\mathrm{Ru}$ by $\mathrm{Fe}$ in tris(bipyridines) and tris(phenanthrolines), while OEPs exhibit a more subtle behavior. (2) The origin of this shift can be traced to a chemical shift of the $\mathrm{N} 1 s$ core level, caused by electron charge transfer from the metal to the surrounding nitrogens. (3) This charge transfer is larger for $\mathrm{Fe}$ than for $\mathrm{Ru}$, due to the lower electronegativity of $\mathrm{Fe}$.

\section{EXPERIMENTAL}

\section{A. Materials}

Ruthenium(II) tris(bipyridine) $\quad \mathrm{Ru}(\mathrm{bpy})_{3}^{2+}, \quad$ iron(II) tris(bipyridine) $\mathrm{Fe}(\mathrm{bpy})_{3}^{2+}$, ruthenium(II) tris(phenanthroline) $\mathrm{Ru}(\text { phen })_{3}^{2+}$, iron(II) tris(phenanthroline) $\mathrm{Fe}(\text { phen })_{3}^{2+}$, more commonly known as the redox indicator ferroin, ruthenium(II) carbonyl octaethyl porphine RuCO-OEP, iron(III) chloride octaethyl porphine FeCl-OEP, $\mathrm{H}_{2}$ octaethyl porphine $\mathrm{H}_{2}$-OEP, bathophenanthroline, and dimethyl phenanthroline were purchased from Sigma-Aldrich and used as received. Carboxylated bipyridine (also known as biisonicotinic acid) was deposited on a smooth layer of $\mathrm{ZnO}$ nanoparticles. $\mathrm{Ru}(\mathrm{bpy})_{3}^{2+}, \mathrm{Fe}(\mathrm{bpy})_{3}^{2+}$, Ru(phen $)_{3}^{2+}$, bathophenanthroline, and dimethyl phenanthroline were dissolved in ethanol and drop cast on Au-coated Si wafers. Fe(phen) ${ }_{3}^{2+}$ was purchased in aqueous solution and drop cast on Au-coated Si.

The best quality spectra (with the narrowest peaks and largest peak-to-valley ratios) were obtained from in situ sublimed samples. However, sublimation was not suitable for all dye molecules, as some of them decomposed before reaching sufficient vapor pressure (Fig. 1). Typical decay products were nitriles, which give rise to a characteristic $\pi *$ peak at 399.9 eV (Ref. 50). Drop casting was also used. Spectra from such samples showed only weak dependence on the solvent, 


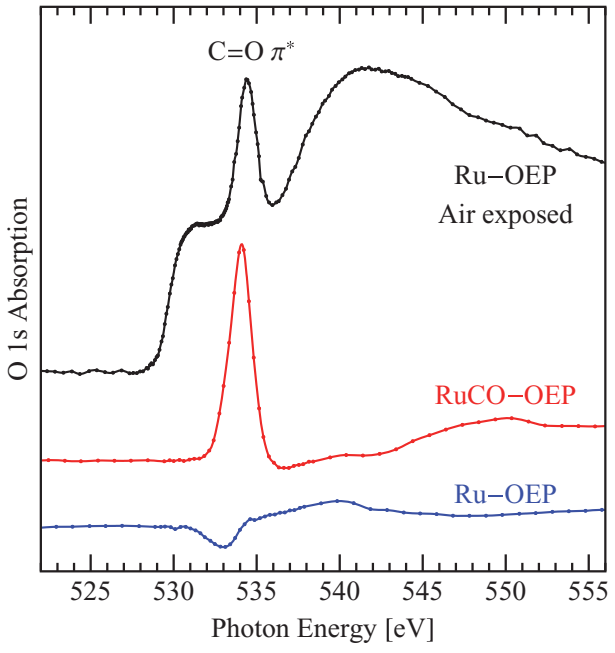

FIG. 1. O $1 s$ spectrum of RuCO-OEP sublimed at $253 \pm 5^{\circ} \mathrm{C}$ (center), compared to that of Ru-OEP sublimed at $415 \pm 5{ }^{\circ} \mathrm{C}$ (bottom), where the $\mathrm{CO}$ ligand is thermally desorbed. Correspondingly, the characteristic $\pi^{*}$ transition of the axial $\mathrm{CO}$ ligand disappears. It reappears after exposure to air (top).

as long as pure solvents without aqueous contamination were used.

Thermal desorption was used to remove the axial $\mathrm{CO}$ ligand from RuCO-OEP at about $400{ }^{\circ} \mathrm{C}$, well above the typical OEP sublimation temperature of $250^{\circ} \mathrm{C}$ (Fig. 1). However, this requires that the axial ligand be less strongly bound than the porphyrin ring. For $\mathrm{FeCl}-\mathrm{OEP}$, the porphyrin ring breaks before $\mathrm{Cl}$ is removed (see Fig. 2).

\section{B. X-ray absorption measurements}

$\mathrm{X}$-ray absorption measurements were performed at two undulator beamlines: Beamline 8.0 of the ALS and the VLSPGM beamline at the SRC. At the ALS it was possible to simultaneously acquire surface-sensitive total electron yield

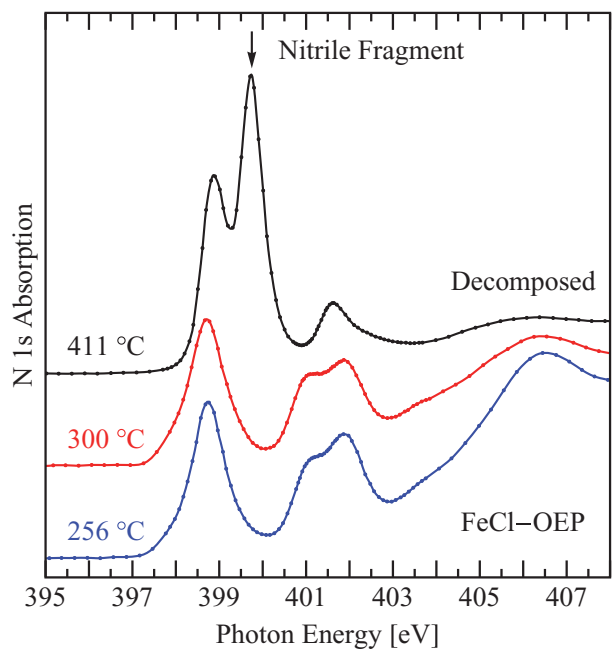

FIG. 2. Preparation of a well-ordered thin film of FeCl-OEP dye molecules by in situ sublimation (bottom and center). Care needs to be taken to keep the sublimation temperature below the decomposition temperature. At higher temperatures $\left(411 \pm 5{ }^{\circ} \mathrm{C}\right.$, top), nitrile fragments can be detected at the $\mathrm{N} 1 s$ edge by their characteristic $\pi^{*}$ peak at $399.9 \mathrm{eV}$ (see Figs. 6(b) and 6(c) in Ref. 50).
(TEY) spectra and bulk-sensitive total fluorescence yield spectra. Details of the experimental setup have been reported in Refs. 50 and 53. For measuring the small energy shifts at the $\mathrm{N} 1 s$ edge, it was necessary to ensure that the photon energy was stable. Therefore, analogous spectra of Fe- and Rubased molecules were taken right after each other. The absolute photon energy calibration was checked frequently by measuring the $\mathrm{C} 1 s$ edge of graphite at grazing incidence, the Ti $2 p$ edge of rutile $\mathrm{TiO}_{2}$, and the $\mathrm{Ni} 2 p$ edge of a Ni mesh. Details about the energy calibration and resolution can be found in Ref. 50.

\section{Density functional theory calculations}

Density functional theory calculations were carried out by means of the Amsterdam density functional code. ${ }^{54}$ All atoms were described through basis sets of TZP quality (triple- $\zeta$ STO plus one polarization function) given in the program database, including all the core electrons in the calculation (i.e., with no frozen core approximation). The exchangecorrelation energy was computed according to the local density approximation by means of the Vosko-Wilk-Nusair ${ }^{55}$ functional. The first step of the calculations consists of obtaining the structures of the different OEPs in their ground state. In a second step, the $\mathrm{N} 1 s$-to-LUMO transition was calculated using the $\triangle \mathrm{SCF}$ method. We have also performed DFT calculations using the transition state (TS) theory proposed by Slater. The details of the $\triangle \mathrm{SCF}$ and TS methods are described in Ref. 7.

\section{RESULTS}

\section{A. $\mathrm{N} 1 s$ absorption spectra}

Figure 3 compares the $\mathrm{N} 1 s$ absorption spectra of various bipyridines. For $\mathrm{Ru}(\mathrm{bpy})_{3}^{2+}$ and $\mathrm{Fe}(\mathrm{bpy})_{3}^{2+}$, the bulk-sensitive

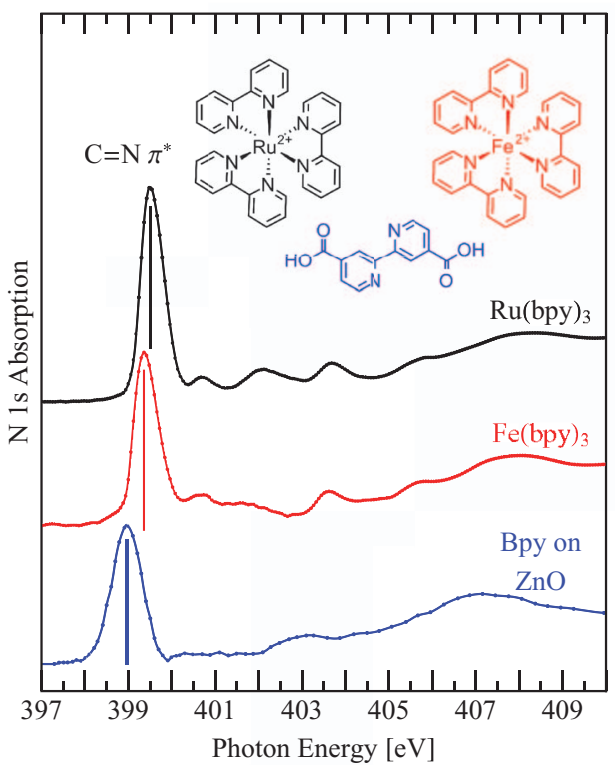

FIG. 3. N $1 s$ spectra of bipyridine-based molecules. The lowest $\mathrm{N} 1 s$-to- $\pi^{*}$ transition shifts down by $0.15 \mathrm{eV}$ when replacing Ru by Fe, due to a decrease in the $\mathrm{N} 1 s$ core level binding energy that is caused by an extra transfer of negative charge from $\mathrm{Fe}$ to the $\mathrm{N}$ ligands. 


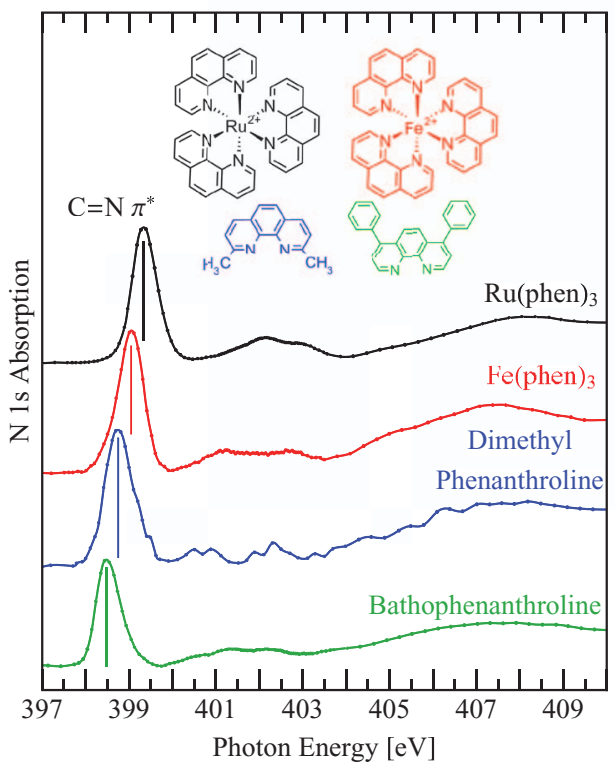

FIG. 4. N $1 s$ spectra of phenanthroline-based molecules. The lowest $\mathrm{N} 1 s-$ to- $\pi *$ transition shifts down by $0.3 \mathrm{eV}$ when replacing $\mathrm{Ru}$ by Fe. Similar to the bipyridine-based molecules, the shift is due to a decrease in the $\mathrm{N} 1 s$ core level binding energy.

fluorescence yield spectra are shown (in order to eliminate the contribution from surface oxides), and for metal-free carboxylated bipyridine on $\mathrm{ZnO}$ the electron yield spectrum. The dominant peak in all spectra is the transition from the $\mathrm{N} 1 s$ core level to the lowest $\pi^{*}$ orbital below $400 \mathrm{eV}$. Weaker transitions into higher-lying $\pi *$ orbitals are visible in the 400$405 \mathrm{eV}$ range, plus a broad $\sigma^{*}$ resonance near $408 \mathrm{eV}$. When going from $\mathrm{Ru}$ - to Fe-tris(bipyridine), the dominant $\pi *$ peak shifts down in energy by $0.15 \mathrm{eV}$. The next three peaks shift in the same direction, indicating a common contribution from a shift of the $\mathrm{N} 1 s$ core level induced by charge transfer. This is confirmed by the calculations in Sec. IV A, where the $\mathrm{N} 1 s$ core level shifts, while the LUMO stays constant. A common shift of two $\pi^{*}$ peaks is also observed at the C $1 s$ edge of the bipyridine-based molecules (see Sec. III B).

Figure 4 shows the $\mathrm{N} 1 s$ absorption spectra for a series of phenanthrolines in the TEY mode, i.e., $\mathrm{Ru}(\mathrm{phen})_{3}^{2+}$, $\mathrm{Fe}(\text { phen })_{3}^{2+}$, together with metal-free dimethyl phenanthroline and bathophenanthroline. The spectra are again dominated by the lowest $\pi^{*}$ transition, with weaker $\pi^{*}$ and $\sigma^{*}$ features at higher energy. Analogous to the bipyridine molecules, a downward energy shift of the lowest $\pi^{*}$ peak is observed going from $\mathrm{Ru}$ to $\mathrm{Fe}$ (here $0.3 \mathrm{eV}$ ), together with a further downshift for the metal-free variants. The noisy signal from dimethyl phenanthroline is due to its higher vapor pressure, which causes bursts of molecules to desorb from the substrate during the measurement.

Figure 5 is analogous to Figs. 3 and 4, but for OEP molecules. They exhibit a planar cage of four nitrogens around the metal atom instead of three-dimensional cage of six $\mathrm{N}$ atoms. The $\mathrm{N} 1 s$ absorption spectra are given for RuCOOEP, Ru-OEP, FeCl-OEP, and $\mathrm{H}_{2}$-OEP, all in the TEY mode. For Ru-OEP, the $\mathrm{CO}$ ligand was removed by sublimation at a higher temperature, as shown in Fig. 1. The metal-OEPs gen-

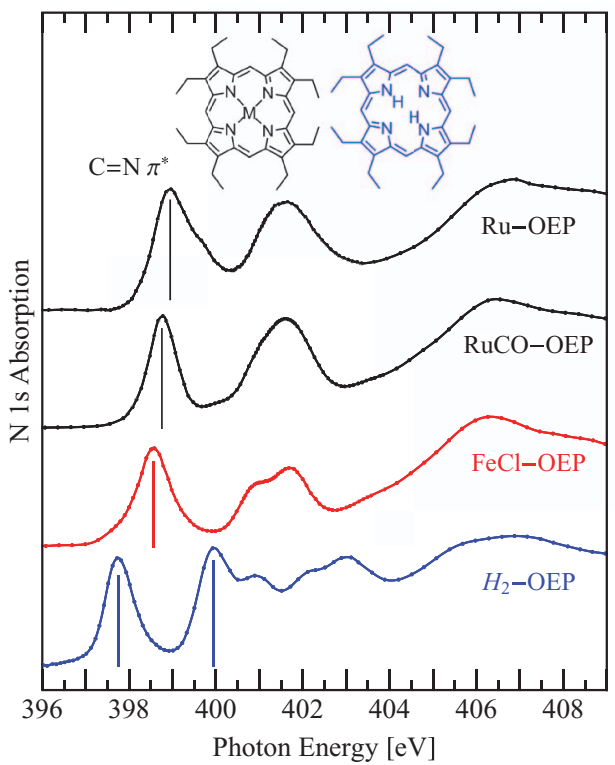

FIG. 5. N $1 s$ spectra of OEP-based molecules. The lowest N $1 s$-to- $\pi *$ transition shifts down by $0.2 \mathrm{eV}$ going from RuCO-OEP to FeCl-OEP (second and third curves). Removal of the CO ligand from RuCO-OEP increases the transition energy by $0.2 \mathrm{eV}$ (top curve). $\mathrm{In}_{2}-\mathrm{OEP}$, the lowest $\pi *$ transition splits because of two inequivalent $\mathrm{N}$ atoms (bottom curve).

erally exhibit smaller shifts of the lowest $\pi *$ peak than the molecules with three-dimensional cages in Figs. 3 and 4. In the metal-free $\mathrm{H}_{2}$-OEP, the lowest $\pi *$ peak is split, because there are two pairs of inequivalent $\mathrm{N}$ atoms (one pair bonding to $\mathrm{H}$, the other not). The lower peak $(397.75 \mathrm{eV})$ is due to the $\mathrm{H}$-free $\mathrm{N}$ atoms, and the higher peak $(399.95 \mathrm{eV})$ to the $\mathrm{N}$ bonded to $\mathrm{H}$ (see the two vertical lines in the bottom curve of Fig. 5).

The energies of the lowest $\mathrm{N} 1 s$-to- $\pi *$ transitions marked by lines in Figs. 3-5 are summarized in Table I. The origin of the energy shifts will be investigated in Sec. IV.

\section{B. C $1 s$ absorption spectra}

Figure 6 shows the $\mathrm{C} 1 s$ fluorescence yield spectra of $\mathrm{Ru}(\mathrm{bpy})_{3}^{2+}, \mathrm{Fe}(\mathrm{bpy})_{3}^{2+}$, and the electron yield spectrum of carboxylated bipyridine on $\mathrm{ZnO}$. Compared to the $\mathrm{N} 1 s$ edge in Fig. 3, the shifts of the LUMO transition are in the opposite

TABLE I. Observed N $1 s$-to- $\pi *$ transition energies.

\begin{tabular}{lc}
\hline Molecule & Transition energy [eV] \\
\hline $\mathrm{Ru}(\mathrm{bpy})_{3}^{2+}$ & $399.51( \pm 0.05)$ \\
$\mathrm{Fe}(\mathrm{bpy})_{3}^{2+}$ & 399.36 \\
Bipyridine on ZnO & 398.97 \\
\hline $\mathrm{Ru}(\text { phen })_{3}^{2+}$ & 399.34 \\
$\mathrm{Fe}(\text { phen })_{3}^{2+}$ & 399.05 \\
Dimethyl phenanthroline & 399.75 \\
Bathophenanthroline & 399.48 \\
\hline $\mathrm{Ru}-\mathrm{OEP}$ & 398.95 \\
$\mathrm{RuCO}-\mathrm{OEP}$ & 398.76 \\
FeCl-OEP & 398.56 \\
$\mathrm{H}_{2}-\mathrm{OEP}$ & $397.75,399.95$ \\
\hline \hline
\end{tabular}




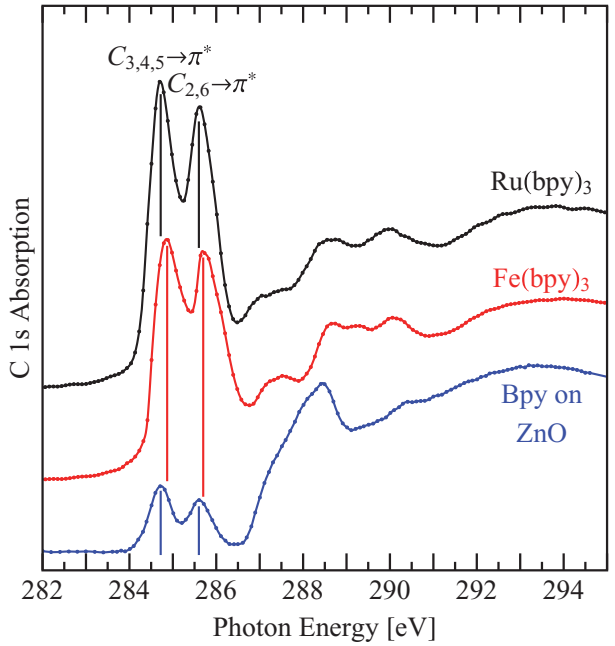

FIG. 6. C $1 s$ spectra of bipyridine-based molecules. The C $1 s$-to- $\pi *$ transition energy increases by $0.15 \mathrm{eV}$ when replacing $\mathrm{Ru}$ by Fe. The second $\pi^{*}$ transition at higher energy shifts by the same amount, suggesting a transition into the same $\pi^{*}$ orbital from a second set of $\mathrm{C}$ atoms with higher binding energy (those binding to $\mathrm{N}$ ).

direction at the $\mathrm{C} 1 s$ edge. Instead of a $0.15 \mathrm{eV}$ downward shift at the $\mathrm{N} 1 s$ edge one observes an upward shift of 0.15 $\mathrm{eV}$ for $\mathrm{C} 1 s$ when going from $\mathrm{Ru}$ to $\mathrm{Fe}$. A second strong $\pi^{*}$ transition is observed at $0.8-0.9 \mathrm{eV}$ higher energy. The two $\pi^{*}$ peaks are assigned to transitions into the same $\pi *$ orbital, but from inequivalent $\mathrm{C}$ atoms. The lower peak is assigned to the three $\mathrm{C}$ atoms bonded to other carbons $\left(\mathrm{C}_{3,4,5}\right)$ and the upper peak to the two $C$ atoms bonded to nitrogen $\left(C_{2,6}\right)$. The latter has higher binding energy due to electronic charge transfer from $\mathrm{C}$ to $\mathrm{N}$. The two corresponding $\mathrm{C} 1 s$ core levels have been observed by XPS ${ }^{12}$ with a similar splitting (about 1.0 $\mathrm{eV}$ ), similar intensity ratio (3:2), and the same assignment. Both $\pi^{*}$ transitions shift by a similar amount, indicating a similar charge transfer to both types of $\mathrm{C}$ atoms via the common $\pi$ system. The sign of the shift indicates removal of electronic charge from the $\pi$ system.

Figure 7 shows a similar trend in the $\mathrm{C} 1 \mathrm{~s}$ spectra of $\mathrm{Ru}(\mathrm{phen})_{3}^{2+}, \mathrm{Fe}(\mathrm{phen})_{3}^{2+}$, dimethyl phenanthroline, and bathophenanthroline. Again there is an upward shift of the LUMO peak when going from Ru to $\mathrm{Fe}$ (by $0.05 \mathrm{eV}$ ), compared to a downward shift at the $\mathrm{N} 1 s$ edge in Fig. 4 (by 0.3 $\mathrm{eV})$. It is tempting to assign the three strong $\pi^{*}$ peaks to transitions from three inequivalent $\mathrm{C}$ atoms into the same, delocalized $\pi^{*}$ system, as in the tris(bipyridines). In contrast to the tris(bipyridine) dyes, the magnitude of this $\mathrm{C} 1 s$ shift is significantly smaller, pointing toward a delocalization of the charge transfer over the larger $\pi$ system of phenanthroline.

In bathophenanthroline, the extra phenyl groups are responsible for the dominant $\mathrm{C}=\mathrm{C} \pi *$ feature which obscures the double peaks seen in the other phenanthroline-based molecules. The low-energy shoulder in the bathophenanthroline spectrum lies close to the lowest $\pi^{*}$ peaks of the other molecules.

Figure 8 shows the $\mathrm{C} 1 s$ spectra for Ru-OEP, RuCOOEP, FeCl-OEP, and $\mathrm{H}_{2}$-OEP. Unlike for the other molecules, the lowest $\pi *$ peak shifts upward when going from $\mathrm{FeCl}$ - to $\mathrm{RuCO}-\mathrm{OEP}$. It shifts further upward when removing the $\mathrm{CO}$ to

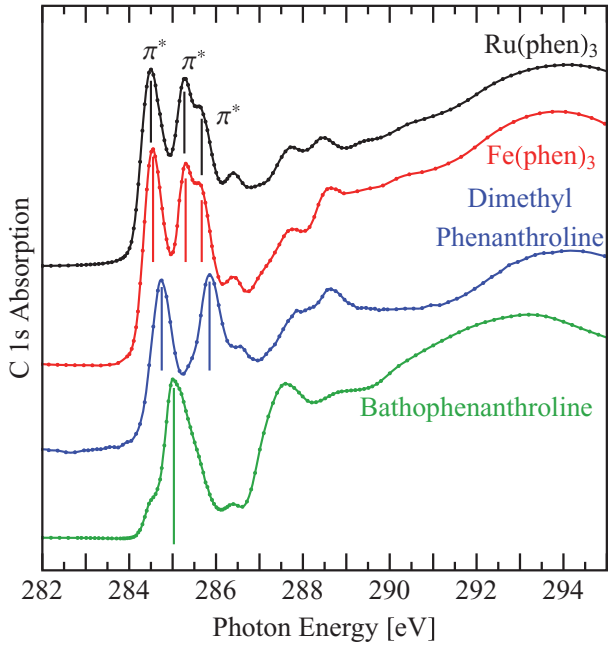

FIG. 7. C $1 s$ spectra of phenanthroline-based molecules. The C $1 s$-to- $\pi *$ transition energy increases by $0.05 \mathrm{eV}$ when replacing Ru by Fe. The smaller shift compared to the bipyridine-based molecules is likely due to delocalization of the charge transfer over the larger $\pi$ system of phenanthroline.

form Ru-OEP. The magnitude of each of these shifts is about $0.1 \mathrm{eV}$. The energies of the $\mathrm{C} 1 s$ transitions marked by lines in Figs. 6-8 are summarized in Table II.

\section{DISCUSSION}

\section{A. Systematic shift at the $\mathrm{N} 1 \mathrm{~s}$ edge}

The key trend at the $\mathrm{N} 1 s$ absorption edge is a systematic downward shift of the $\mathrm{N} 1 s$-to- $\pi *$ transition when going from $\mathrm{Ru}$ to $\mathrm{Fe}$ (and eventually to metal-free dye molecules). Such a shift can be explained by transfer of negative charge from the metal to the neighboring $\mathrm{N}$ atoms, as investigated in more detail in previous work on $3 d$ metal OEPs. ${ }^{7}$ The smaller electronegativity of $\mathrm{Fe}$ compared to $\mathrm{Ru}$ increases the transfer of negative charge from $\mathrm{Fe}$ to its $\mathrm{N}$ ligands, thus decreasing the binding energy of the $\mathrm{N} 1 s$ electrons. This model is supported

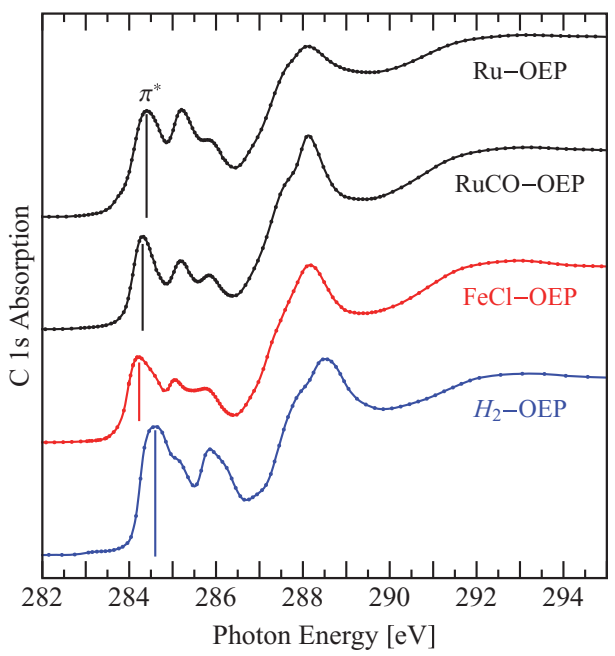

FIG. 8. C $1 s$ spectra of OEP-based molecules with a planar $\mathrm{N}$ cage. The $\mathrm{C}$ $1 s$-to- $\pi *$ transition energy decreases by about $0.1 \mathrm{eV}$ when going from $\mathrm{Ru}-$ to Fe-based OEPs, opposite to the behavior of the dye molecules with threedimensional cages in Figs. 6 and 7. 
TABLE II. Observed C $1 s$-to- $\pi *$ transition energies.

\begin{tabular}{lc}
\hline \hline Molecule & Transition energies [eV] \\
\hline Ru(bpy) 3 & $284.72,285.60( \pm 0.05)$ \\
Fe(bpy) 3 & $284.87,285.70$ \\
Bipyridine on $\mathrm{ZnO}$ & $284.72,285.60$ \\
\hline Ru(phen) $)_{3}$ & $284.50,285.27,285.67$ \\
Fe(phen) 3 & $284.55,285.30,285.67$ \\
Dimethyl phenanthroline & $284.75,285.85$ \\
Bathophenanthroline & 285.03 \\
\hline Ru-OEP & 284.40 \\
RuCO-OEP & 284.31 \\
FeCl-OEP & 284.23 \\
$\mathrm{H}_{2}$-OEP & 284.60 \\
\hline \hline
\end{tabular}

by XPS measurements of the N $1 s$ core level and the HOMO for the Fe-, Ru-, Os-tris(bipyridine) series. ${ }^{12}$ From $\mathrm{Ru}$ to $\mathrm{Fe}$, the $\mathrm{N} 1 s$ level shifts up by $0.08 \mathrm{eV}$ and the HOMO shifts up by $0.35 \mathrm{eV} .^{12}$ This gives an upwards shift of $0.27 \mathrm{eV}$ for the binding energy of the $\mathrm{N} 1 s$ relative to the HOMO, which parallels the observed upward shift of $0.15 \mathrm{eV}$ for the $\mathrm{N} 1 s$-to- $\pi *$ transition.

While the $\mathrm{N}$ atoms in the tris(bipyridine) and tris(phenanthroline) molecules exhibit a sixfold, approximately octahedral arrangement around the metal, ${ }^{41}$ there are only four $\mathrm{N}$ atoms surrounding the metal in the OEPs. These structures may be viewed as three-dimensional and two-dimensional cages, respectively. Aside from the change in the number of $\mathrm{N}$ ligands, the cage structure also affects the crystal field that splits the metal $d$-levels and shifts the $\mathrm{N} 2 p$ levels. The bonding geometry of the metal atom also affects the oxidation state, which in turn affects the charge transfer to the $\mathrm{N}$ ligands. In particular, $\mathrm{Fe}$ is in the +2 oxidation state in the three-dimensional cages of the tris(bipyridine) and tris(phenanthroline) molecules, whereas it prefers the +3 oxidation state in the two-dimensional, planar cages of OEP or phthalocyanine molecules. $\mathrm{Ru}$, on the other hand, prefers the +2 oxidation state in OEPs and phthalocyanines. ${ }^{14,48}$ As a result, we have only been able to make a direct comparison between $\mathrm{Ru}^{2}+$ in $\mathrm{RuCO}-\mathrm{OEP}$ and $\mathrm{Fe}^{3+}$ in $\mathrm{FeCl}-\mathrm{OEP}$. Removal of the $\mathrm{Cl}$ from $\mathrm{FeCl}-\mathrm{OEP}$ without breaking the molecule apart has not been possible (compare Fig. 2). In order to sort out the contributions from the oxidation state and the axial ligand, we have calculated the electronic structure of $\mathrm{Ru}$ - and Fe-OEPs for various combinations of oxidation states and axial ligands.

\section{B. Calculation of the energy shift}

First-principles DFT calculations of the N $1 s$-to- $\pi *$ transitions were performed for the combinations of metal, oxidation state, and axial ligand that are relevant to our data (RuCO-OEP, FeCO-OEP, RuCl-OEP, FeCl-OEP). The methodology has been tested previously with a series of $3 d$ transition metal OEPs, ${ }^{7}$ where the details of the calculations are described. The results are given in Table III. The $\mathrm{N} 1 s$-to$\pi^{*}$ transition energy can be decomposed into three contributions, i.e., the $\mathrm{N} 1 s$ core level energy, the LUMO energy, and
TABLE III. Calculated N $1 s$-to- $\pi *$ transition energies for $\mathrm{Ru}$ - and FeOEPs. The results for the $\mathrm{N} 1 s$ core level and the LUMO are obtained relative to the vacuum level from a transition state calculation (with 1.5 electrons in the $\mathrm{N} 1 s$ core level), while the $\mathrm{N} 1 s$-to- $\pi *$ transition is obtained from a $\Delta \mathrm{SCF}$ calculation. The $\mathrm{N}$ charge has been obtained using the Bader analysis. ${ }^{57}$

\begin{tabular}{|c|c|c|c|c|c|}
\hline Molecule & $\begin{array}{c}\mathrm{N} 1 s \text {-to- } \pi^{*} \\
{[\mathrm{eV}]}\end{array}$ & $\begin{array}{c}\text { LUMO } \\
{[\mathrm{eV}]}\end{array}$ & $\begin{array}{c}\mathrm{N} 1 s \\
\text { energy } \\
{[\mathrm{eV}]}\end{array}$ & $\begin{array}{c}\mathrm{N} \text { charge } \\
\text { (per atom) }[e]\end{array}$ & $\begin{array}{c}\text { Electron-core } \\
\text { hole interaction } \\
{[\mathrm{eV}]}\end{array}$ \\
\hline RuCO-OEP & 402.56 & -2.62 & -405.20 & -0.959 & 3.16 \\
\hline FeCO-OEP & 402.63 & -2.65 & -405.38 & -0.954 & 3.18 \\
\hline RuCl-OEP & 402.53 & -2.62 & -405.17 & -0.970 & 3.16 \\
\hline $\mathrm{FeCl}-\mathrm{OEP}$ & 402.50 & -2.66 & -405.24 & -0.962 & 3.17 \\
\hline
\end{tabular}

the Coulomb interaction between an electron in the LUMO and the $\mathrm{N} 1 s$ core hole. In previous systematic work, it was found that the largest variation within the $3 d$ metal series was caused by a shift of the N $1 s$ level due to varying charge transfer from the transition metal to the N. ${ }^{12}$ Here, we have to consider two additional effects, the change in the oxidation state and the change from a $3 d$ to a $4 d$ metal. It turns out that these effects have comparable influence on the shifts.

The calculated shifts in Table III reveal some trends for the porphyrins. Going from $\mathrm{Ru}$ to Fe in the same molecule, the $\mathrm{N} 1 s$ level moves down, which is opposite to the trend encountered with the three-dimensional cages. But this is consistent with the calculated charge on the $\mathrm{N}$ atoms which is less negative with $\mathrm{Fe}$. At a first glance, such a charge transfer seems to be at variance with the lower electronegativity of Fe. The calculation reveals that some of the negative charge donated by $\mathrm{Fe}$ is diverted to the axial $\mathrm{Cl}$ ligand, which leaves less negative charge on the $\mathrm{N}$. For example, the $\mathrm{Cl}$ ligand receives a charge of $-0.375 e$ in $\mathrm{FeCl}-\mathrm{OEP}$, while it gets only $-0.335 e$ in $\mathrm{RuCl}-\mathrm{OEP}$.

The LUMO and the electron-hole interaction do not change significantly, analogous to the trend found along the $3 d$ series. ${ }^{7}$ The fact that the LUMO remains nearly unchanged relative to the vacuum level implies that one should not expect a large difference in the band offset between LUMO and acceptor, at least within the approximate electron affinity model. The band offset is an important factor in the back electron transfer. The change in oxidation state shifts the LUMO by at most $0.01 \mathrm{eV}$, which is within the uncertainty of the calculation.

The comparison between theory and experiment for the measured N $1 s$-to- $\pi *$ shift between RuCO-OEP and FeClOEP comes out qualitatively correct in the $\triangle \mathrm{SCF}$ calculation: The calculated shift is $0.06 \mathrm{eV}$ toward lower energy, while the experimental shift is $0.2 \mathrm{eV}$ in the same direction. These shifts are close to the theoretical and experimental accuracy limits and should not be taken quantitatively. The $\triangle \mathrm{SCF}$ method has been recently compared to the more sophisticated timedependent DFT method and was found to give comparable accuracy. ${ }^{56}$

The HOMO is formed by the metal $d_{x y}$ orbital and the HOMO-1 by the $d_{x z, y z}$ and $\mathrm{N} 2 p_{z}$ orbitals, but all three are nearly degenerate in energy. The occupancy of the $d$-orbitals differs from that of Mn-OEP in Ref. 7, because Mn-OEP is 
in the high spin configuration with a total spin of $5 / 2$ for the five $d$ electrons of $\mathrm{Mn}^{2+}$. As a result, all the $d$-levels of $\mathrm{Mn}$ are singly occupied. $\mathrm{Fe}^{2+}$ in $\mathrm{FeCO}-\mathrm{OEP}$ and $\mathrm{Ru}^{2+}$ in RuCOOEP contain six $d$-electrons, and these are in the low spin state with total spin 0. Consequently, the three lowest $d$-levels of $\mathrm{Fe}$ and $\mathrm{Ru}$ are doubly occupied, and the two uppermost $d$-levels are empty. The occupied $d$-levels are derived from $t_{2 g}$ states, and the unoccupied $d$-levels $e_{g}$.

In order to compare the differences between $\mathrm{Ru}$ and $\mathrm{Fe}$, we have investigated the degree of hybridization between their states and its relation to the bond length. The $\mathrm{Fe}-\mathrm{N}$ distance in $\mathrm{FeCO}-\mathrm{OEP}$ is $0.08 \AA$ shorter than the Ru- $\mathrm{N}$ distance in RuCO-OEP (both in the same oxidation state). In the threedimensional cage molecules $\mathrm{Fe}(\mathrm{bpy})_{3}^{2+}$ and $\mathrm{Ru}(\mathrm{bpy})_{3}^{2+}$, the $\mathrm{Fe}-\mathrm{N}$ bond length is $0.085 \AA$ smaller than the $\mathrm{Ru}-\mathrm{N}$ bond length. ${ }^{41}$ This trend reflects the smaller radius of the $3 d$ wave function in $\mathrm{Fe}$ compared to the $4 d$ wave function in Ru. However, the difference is significantly smaller than $0.13 \AA$, the difference between the ionic radii of $\mathrm{Ru}$ and $\mathrm{Fe}$. The porphyrin ring is too stiff to allow relaxation of the $\mathrm{N}$ atoms to the unconstrained equilibrium bond length with $\mathrm{Fe}$, which is smaller. As a result, the overlap between the $\mathrm{Fe} 3 d$ and $\mathrm{N} 2 p$ orbitals is reduced. This is reflected in the smaller hybridization of the HOMO, i.e., $48 \% \mathrm{Fe} 3 d$ and $10 \% \mathrm{~N} 2 p$ in $\mathrm{FeCO}-$ OEP versus $31 \% \mathrm{Ru} 4 d$ and $15 \% \mathrm{~N} 2 p$ in RuCO-OEP, with the remaining contribution from other orbitals. Note that in both cases the metal atom is displaced from the $\mathrm{N}$ plane due to the axial ligand, Fe by $0.15 \AA$ and Ru by $0.19 \AA$.

\section{Shifts at the C 1 s edge}

The shifts at the $\mathrm{C} 1 s$ edge are smaller than those at the $\mathrm{N} 1 s$ edge due to the increased distance of the $\mathrm{C}$ atoms from the metal. The binding energy of the $\mathrm{C} 1 s$ core level increases when going from $\mathrm{Ru}$ to $\mathrm{Fe}$ in the three-dimensional molecules, but it decreases in the two-dimensional OEP. This difference is most likely due to changes in the $\mathrm{C} 1 s$ binding energy, since different $\pi *$ transitions are shifted by the same amount. A smaller contribution might come from change in the energy of the unoccupied orbitals due to the different structure of the OEPs. Like for the $\mathrm{N} 1 s$ spectrum of $\mathrm{H}_{2}$-OEP, the structure of the $\mathrm{C} 1 s$ spectrum differs from those of the metal OEPs because of the inequivalent $\mathrm{N}$ species, which produce inequivalent $\mathrm{C}$ species. In all the dye molecules, the $\mathrm{C}$ atoms are farther from the metal than the $\mathrm{N}$ atoms and therefore less affected by going from $\mathrm{Ru}$ to $\mathrm{Fe}$. Therefore, we do not attempt to provide an in-depth explanation of the $\mathrm{C} 1 \mathrm{~s}$ shifts. We only comment on the smaller shift of the C $1 s$-to$\pi *$ transitions from Ru to $\mathrm{Fe}$ in tris(phenanthroline) compared to tris(bipyridine) molecules. This could be due to higher delocalization of the LUMO in the larger $\pi$ system of phenanthroline.

\section{CONCLUSIONS}

In summary, we have investigated differences in the electronic structure of $\mathrm{Ru}$ - and Fe-based dyes, in order to find out whether it might be possible to replace Ru by Fe in solar cell applications. A consistent trend is observed in the $\mathrm{N} 1 s \mathrm{X}-$ ray absorption spectra of three-dimensional cage molecules, where the $\mathrm{N} 1 s$-to- $\pi^{*}$ transition shifts down in energy, and the $\mathrm{C} 1 s$-to- $\pi *$ transition shifts up when going from Ru to Fe. This trend is explained by a charge transfer between the metal and the surrounding $\mathrm{N}$ ligands using DFT calculations. Fe transfers more negative charge to its $\mathrm{N}$ ligands than $\mathrm{Ru}$. Smaller and less uniform effects are observed for planar cages. Calculations reveal a delicate balance between several driving forces, such as the oxidation state, the crystal field, the presence of axial ligands, and the delocalization of the $\pi$ system.

The next step in this quest for inexpensive Fe-based dye molecules will be an investigation of the electronic states at the Fe atom, particularly the $3 d$ valence states. The empty part can be probed by X-ray absorption spectroscopy at the Fe $2 p$ edge, which exhibits a rich manifold of sharp Fe $2 p$ to- $3 d$ transitions. ${ }^{52,58}$ Such a study should be able to address how the cage structure of the $\mathrm{Fe}$ atom affects its $3 d$ manifold via the crystal field splitting. That in turn controls the stability of the dye molecules against oxidation, which is one of the major issues with Fe-based molecules.

Another direction would be to test Ru- vs. Fe-based dyes in dye sensitized solar cells or their components. Particularly interesting would be the influence of the observed energy level shifts on the electronic properties, such as internal quantum efficiency and back electron transfer.

\section{ACKNOWLEDGMENTS}

This work was supported by the National Science Foundation (NSF) under Award Nos. CHE-1026245, DMR1121288 (MRSEC), DMR-0537588 (SRC), and by the (U.S.) Department of Energy (DOE) under Contract Nos. DE-FG0201ER45917 (end station) and DE-AC02-05CH11231 (ALS). P. L. Cook acknowledges support from the University of Wisconsin System 2012-2013 Applied Research Grant. J. M. García-Lastra and A. Rubio acknowledge financial support from the European Research Council (ERC-2010-AdGProposal No. 267374), Spanish Grants (FIS2011-65702C02-01 and PIB2010US-00652), Grupos Consolidados (IT319-07), and European Commission project CRONOS (280879-2).

${ }^{1}$ M. Grätzel, Nature (London) 414, 338 (2001).

${ }^{2}$ P. L. Cook, X. Liu, W. Yang, and F. J. Himpsel, J. Chem. Phys. 131, 194701 (2009).

${ }^{3}$ G. Bauer and K. A. Kirchner, Angew. Chem., Int. Ed. 50, 5798 (2011).

${ }^{4}$ M. G. Walter, A. B. Rudine, and C. C. Wamser, J. Porphyr. Phthalocyanines 14, 759 (2010).

${ }^{5}$ A. Hagfeldt and M. Grätzel, Acc. Chem. Res. 33, 269 (2000).

${ }^{6}$ A. Yella, H.-W. Lee, H. N. Tsao, C. Yi, A. K. Chandiran, M. Nazeeruddin, E. W.-G. Diau, C.-Y. Yeh, S. M. Zakeeruddin, and M. Grätzel, Science 334, 629 (2011).

${ }^{7}$ J. M. García-Lastra, P. L. Cook, F. J. Himpsel, and A. Rubio, J. Chem. Phys. 133, 151103 (2010).

${ }^{8}$ P. L. Cook, W. Yang, X. Liu, J. M. García-Lastra, A. Rubio, and F. J. Himpsel, J. Chem. Phys. 134, 204707 (2011).

${ }^{9}$ J. Åhlund, K. Nilson, J. Schiessling, L. Kjeldgaard, S. Berner, N. Mårtensson, C. Puglia, B. Brena, M. Nyberg, and Y. Luo, J. Chem. Phys. 125, 034709 (2006) 
${ }^{10}$ M. P. de Jong, R. Friedlein, S. L. Sorensen, G. Öhrwall, W. Osikowicz, C. Tengsted, S. K. M. Jönsson, M. Fahlman, and W. R. Salaneck, Phys. Rev. B 72, 035448 (2005).

${ }^{11}$ M.-S. Liao and S. Scheiner, J. Chem. Phys. 114, 9780 (2001).

${ }^{12}$ E. M. J. Johansson, M. Odelius, S. Plogmaker, M. Gorgoi, S. Svensson, H. Siegbahn, and H. Rensmo, J. Phys. Chem. C 114, 10314 (2010).

${ }^{13}$ E. Johansson, M. Odelius, M. Gorgoi, O. Karis, R. Ovsyannikov, F. Schäfers, S. Svensson, H. Siegbahn, and H. Rensmo, Chem. Phys. Lett. 464, 192 (2008).

${ }^{14}$ G. Liu, A. Klein, A. Thissen, and W. Jaegermann, Surf. Sci. 539, 37 (2003).

${ }^{15}$ K. Westermark, H. Rensmo, J. Schnadt, P. Persson, S. Södergren, P. Brühwiler, S. Lunell, and H. Siegbahn, Chem. Phys. 285, 167 (2002).

${ }^{16}$ H. Rensmo, K. Westermark, S. Södergren, O. Kohle, P. Persson, S. Lunell, and H. Siegbahn, J. Chem. Phys. 111, 2744 (1999).

${ }^{17}$ R. J. Crutchley and A. B. P. Lever, Inorg. Chem. 21, 2276 (1982).

${ }^{18}$ G. Benkö, P. Myllyperkiö, J. Pan, A. P. Yartsev, and V. Sundström, J. Am. Chem. Soc. 125, 1118 (2003).

${ }^{19}$ P.-S. Kim, T.-K. Sham, P. Zhang, M.-K. Fung, S.-T. Lee, Y.-F. Hu, and B. W. Yates, J. Am. Chem. Soc. 123, 8870 (2001).

${ }^{20}$ A. T. Yeh, C. V. Shank, and J. K. McCusker, Science 289, 935 (2000).

${ }^{21}$ N. H. Damrauer, G. Cerullo, A. Yeh, T. R. Boussie, C. V. Shank, and J. K. McCusker, Science 275, 54 (1997).

${ }^{22}$ Y. Tachibana, J. E. Moser, M. Grätzel, D. R. Klug, and J. R. Durrant, J. Phys. Chem. 100, 20056 (1996).

${ }^{23}$ C. Bressler, C. Milne, V.-T. Pham, A. ElNahhas, R. M. van der Veen, W. Gawelda, S. Johnson, P. Beaud, D. Grolimund, M. Kaiser, C. N. Borca, G. Ingold, R. Abela, and M. Chergui, Science 323, 489 (2009).

${ }^{24}$ W. Gawelda, M. Johnson, F. M. F. de Groot, R. Abela, C. Bressler, and M. Chergui, J. Am. Chem. Soc. 128, 5001 (2006).

${ }^{25}$ N. Huse, H. Cho, K. Hong, L. Jamula, F. M. F. de Groot, T. K. Kim, J. K. McCusker, and R. W. Schoenlein, J. Phys. Chem. Lett. 2, 880 (2011).

${ }^{26}$ N. Huse, T. K. Kim, L. Jamula, J. K. McCusker, F. M. F. de Groot, and R. W. Schoenlein, J. Am. Chem. Soc. 132, 6809 (2010).

${ }^{27}$ L. X. Chen, Annu. Rev. Phys. Chem. 56, 221 (2005).

${ }^{28}$ G. Ma, J. He, C.-H. Kang, and S.-H. Tang, Chem. Phys. Lett. 370, 293 (2003).

${ }^{29}$ J. Schnadt, P. A. Brühwiler, L. Patthey, J. N. O’Shea, S. Södergren, M. Odelius, R. Ahuja, O. Karis, M. Bässler, P. Persson, H. Siegbahn, S. Lunell, and N. Mårtensson, Nature (London) 418, 620 (2002).

${ }^{30}$ E. F. Aziz, M. H. Rittmann-Frank, K. M. Lange, S. Bonhommeau, and M. Chergui, Nat. Chem. 2, 853 (2010).

${ }^{31}$ R. K. Hocking, E. C. Wasinger, Y.-L. Yan, F. M. F. deGroot, F. A. Walker, K. O. Hodgson, B. Hedman, and E. I. Solomon, J. Am. Chem. Soc. 129, 113 (2007).

${ }^{32}$ M. Abrahamsson, M. Jäger, R. J. Kumar, T. Österman, P. Persson, H.C. Becker, O. Johansson, and L. Hammarström, J. Am. Chem. Soc. 130, 15533 (2008).

${ }^{33}$ F. De Angelis, S. Fantacci, A. Selloni, M. K. Nazeeruddin, and M. Grätzel, J. Am. Chem. Soc. 129, 14156 (2007).
${ }^{34}$ A. Vlček, Jr. and S. Záliš, Coord. Chem. Rev. 251, 258 (2007).

${ }^{35}$ P. Persson and M. J. Lundqvist, J. Phys. Chem. B 109, 11918 (2005).

${ }^{36}$ J.-F. Guillemoles, V. Barone, L. Joubert, and C. Adamo, J. Phys. Chem. A 106, 11354 (2002).

${ }^{37}$ S. Gorelsky, E. Dodsworth, A. Lever, and A. Vlcek, Coord. Chem. Rev. 174, 469 (1998).

${ }^{38}$ G. Calzaferri and R. Rytz, J. Phys. Chem. 99, 12141 (1995).

${ }^{39}$ A. B. P. Lever, Inorg. Chem. 29, 1271 (1990).

${ }^{40}$ M. Král, Theor. Chim. Acta 55, 333 (1980).

${ }^{41}$ K. S. Low, J. M. Cole, X. Zhou, and N. Yufa, Acta Crystallogr. 68, 137 (2012).

${ }^{42}$ B. N. Figgis and M. A. Hitchman, Ligand Field Theory and its Applications (Wiley-VCH, 2000), Sec. 7.1.3.

${ }^{43}$ M. Blume, A. J. Freeman, and R. E. Watson, Phys. Rev. 134, A320 (1964).

${ }^{44}$ M. Blume and R. E. Watson, Proc. R. Soc. London, Ser. A 271, 565 (1963).

${ }^{45}$ M. Srnec, J. Chalupský, M. Fojta, L. Zendlová, L. Havran, M. Hocek, M. Kývala, and L. Rulíšek, J. Am. Chem. Soc. 130, 10947 (2008).

${ }^{46}$ F. Felix, J. Ferguson, H. U. Guedel, and A. Ludi, J. Am. Chem. Soc. 102, 4096 (1980).

${ }^{47}$ S. Decurtins, F. Felix, J. Ferguson, H. U. Guedel, and A. Ludi, J. Am. Chem. Soc. 102, 4102 (1980).

${ }^{48}$ M. K. R. Fischer, I. Lopez-Duarte, M. M. Wienk, M. V. Martinez-Díaz, R. A. J. Janssen, P. Bäuerle, and T. Torres, J. Am. Chem. Soc. 131, 8669 (2009).

${ }^{49}$ P. L. Cook, P. S. Johnson, X. Liu, A.-L. Chin, and F. J. Himpsel, J. Chem. Phys. 131, 214702 (2009).

${ }^{50}$ P. S. Johnson, P. L. Cook, X. Liu, W. Yang, Y. Bai, N. L. Abbott, and F. J. Himpsel, J. Chem. Phys. 135, 044702 (2011); in prior work, ${ }^{2,7,8}$ a $0.2 \mathrm{eV}$ higher value was used for the Ti $2 p$ reference energy for the $\mathrm{N} 1 s$ edge. Here, we use a more accurate energy calibration via the $\pi *$ transitions in $\mathrm{N}_{2}$.

${ }^{51}$ P. L. Cook, P. S. Johnson, I. Zegkinoglou, and F. J. Himpsel, "Electronic structure of Fe-based dye molecules in planar vs. octahedral cages" (unpublished).

${ }^{52}$ F. Himpsel, P. Cook, G. de la Torre, J. García-Lastra, R. Gonzalez-Moreno, J.-H. Guo, R. Hamers, C. Kronawitter, P. Johnson, J. Ortega, D. Pickup, M.-E. Ragoussi, C. Rogero, A. Rubio, R. Ruther, L. Vayssieres, W. Yang, and I. Zegkinoglou, "Design of solar cell materials via soft X-ray spectroscopy," J. Electron Spectrosc. Relat. Phenom. (in press).

${ }^{53}$ P. S. Johnson, P. L. Cook, X. Liu, W. Yang, Y. Bai, N. L. Abbott, and F. J. Himpsel, J. Phys. Chem. B 116, 7048 (2012).

${ }^{54}$ G. te Velde, F. M. Bickelhaupt, E. J. Baerends, C. F. Guerra, S. J. A. van Gisbergen, J. G. Snijders, and T. Ziegler, J. Comput. Chem. 22, 931 (2001).

${ }^{55}$ S. H. Vosko, L. Wilk, and M. Nusair, Can. J. Phys. 58, 1200 (1980).

${ }^{56}$ T. Kowalczyk, S. R. Yost, and T. V. Voorhis, J. Chem. Phys. 134, 054128 (2011).

${ }^{57}$ J. I. Rodríguez, R. F. Bader, P. W. Ayers, C. Michel, A. W. Götz, and C. Bo, Chem. Phys. Lett. 472, 149 (2009).

${ }^{58}$ E. Stavitski and F. M. de Groot, Micron 41, 687 (2010). 